\title{
FEM Analysis Of Stamping Process For Vehicle Cowl Inner Panel
}

$$
\text { Huajun Yan }{ }^{1,2, a,{ }^{*}} \text {, Shibo Ma }{ }^{1,2, b} \text {, Lijuan Wang }{ }^{1,2, c} \text {, Ying Gao }{ }^{1,2, d}
$$

${ }^{1}$ School of Materials Science and Engineering, Hebei University of Science and Technology, Hebei Key Laboratory of Material Near-net Forming Technology, Shijiazhuang 050018, China

\author{
${ }^{2}$ Hebei Engineering Technology Research Center of Precision Punching Process and Die, \\ Cangzhou 061500, China \\ ayanhj22@163.com, 'bmashibo1980@163.com, ' kdwlj@163.com, ' ${ }^{\mathrm{b}}$ gaoyingch@sina.com, "correspo \\ nding author
}

Keywords: cowl inner panel; addendum surface; binder force; numerical simulation

\begin{abstract}
As the important component for bearing collision in the front of the vehicle, the cowl inner panel has complex shape features such as bulges, reinforcing ribs and holes. When the panel is formed, defects of wrinkling, cracking or incomplete forming will occor. The drawing die is designed for a certain type of the cowl inner panel, and the drawing process is simulated using analysis software Dynaform, and influence laws of the binder force and fillet radii of addendum surface are researched, and process parameters are optimized, that is the binder force $F$ equals to $500 \mathrm{kN}$, the fillets $r_{1}$ equals to $25 \mathrm{~mm}, r_{2}$ equals to $25 \mathrm{~mm}$. The conclusion has a certain effect on forming parts with high quality.
\end{abstract}

\section{Introduction}

Cowl panel is the bulkhead between the engine room and the cab, and the important component for bearing collision in the front of the vehicle. There are defferent types of reinforcing ribs and bulges on the part to ensure enough strength and stiffness. There are also many holes on the part to instal lines, so good quality parts to be formed need to adopt suitable stamping process and process parameters[1].

The numerical simulation technology of metal sheet is the technology of using analysis software to simulate the forming process of the sheet, which can analyze all kinds of stamping problem encountered in the forming process, such as products formability, local wrinkling, spingback, tonnage prediction of stamping, layout of drawing rib, design and optimization of products and dies[2-4]. Each simulation is equivalent to a tryout process, so sophisticated simulation technology can reduce the number of experiments[5]. The qualified die and process design can also once obtain under certain simulation condition, which can greatly shorten the development cycle of new products, reduce development costs, and improve product quality and market competitiveness[6-7]. In this paper, the simulation technology is used to simulate the forming process of the cowl inner panel and the forming rules of the parts are analyzed, and the process parameters are optimized.

\section{Create Finite Element Model}

A type of cowl inner panel is shown in Figure 1. The material of the part is DP600, and the chickness of the sheet is $0.7 \mathrm{~mm}$, and the material properties are shown in Table 1 . There are a big drawing bulge, a lot of ribs and holes on the parts. Because of the complex shape, thin thickness of sheet and asymmetric structure, the formability of the part is poor. The complete stamping process of the part includes drawing, punching, flanging, trimming and reshaping process.

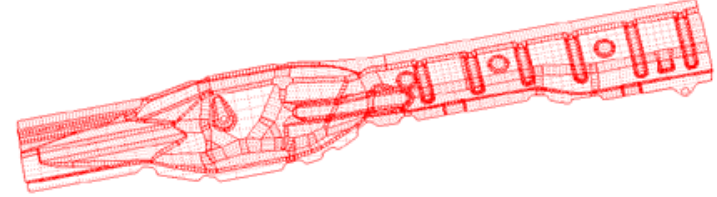

Figure 1. Model of cowl inner panel 
Table 1 Material properties of DP600

\begin{tabular}{ccccccc}
\hline $\begin{array}{c}\text { Material } \\
\text { type }\end{array}$ & $\begin{array}{c}\text { Elastic } \\
\text { modulus/GPa }\end{array}$ & $\begin{array}{c}\text { Yield strength } \\
\text { /MPa }\end{array}$ & $\begin{array}{c}\text { Tensile strength } \\
\text { /MPa }\end{array}$ & $\begin{array}{c}\text { Elongation } \\
\text { /\% }\end{array}$ & $\mathrm{n}$ & $\mathrm{r}$ \\
\hline DP600 & 220 & 351 & 633 & 28 & 0.17 & 0.67 \\
\hline
\end{tabular}

\section{Design of Drawing Die}

The quality of the part drawed will directly affect the quality of the part in the subsequent processes, so drawing is the most important process in all processes. The design of drawing die can be made by the 3D modeling software or by finite element analysis software Dynaform. The design includes determining the appropriate stamping direction, filling internal holes of the part, design of the binder and addendum surface, etc. The design of drawing die should meet the principle that drawing depth of the sheet is uniform and deformation of the metal is even and full. The finite element model of the drawing die is shown in Figure 2.

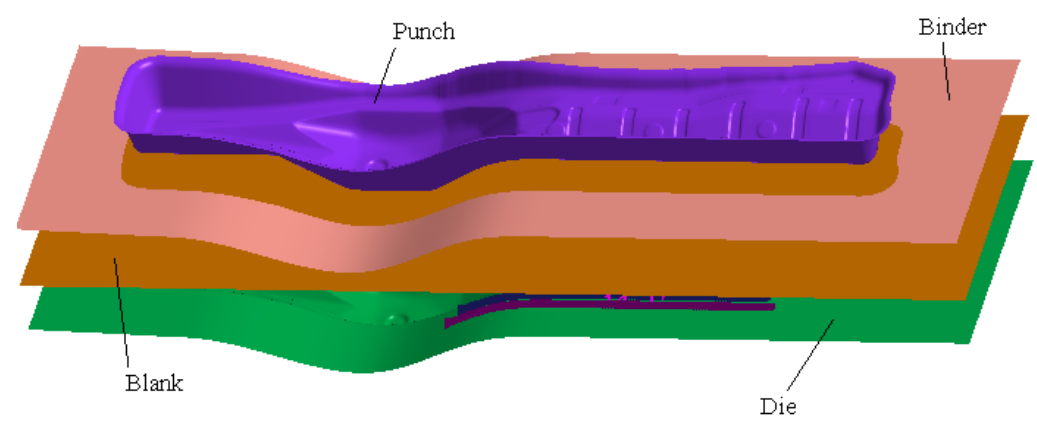

Figure 2. Finite element model of the drawing die

\section{Effect of Process Parameters on Forming Properties}

The fillets radii of addendum surface and the binder force are two important process parameters in the forming processes of the panel. The type of addendum surface is shown in Figure 3. r1 and r2 are respectively die fillet radius and punch fillet radius, the angle between the inclined plane and the direction of stamping is $\alpha$. The theoretical calculation formula of the binder force is shown in Formula 1, and the binder force $\mathrm{F}$ caculated is approximately $1295 \mathrm{kN}$. The setting of process parameters need to consult the theoretical values or empirical data, and the process parameters of simulation are shown in Table 2. The die clearence $C$ takes usually the experience value, that is $C=$ $1.1 \mathrm{t}$ ( $\mathrm{t}$ is the thickness of sheet). The effects of fillets radii of addendum surface and binder force on the drawing are researched, and the process parameters are optimized. When the fillets radii of addendum surface are analyzed, binder force is selected $1300 \mathrm{kN}$, and when the binder force condition is analyzed, the fillets radii of r1 and r2 are all selected $25 \mathrm{~mm}$.

$$
F=q A
$$

Where, $A$ is the projection area of blank on the flange, $q$ is the binder force per unit area, and generally $q$ is $2 \mathrm{MPa}$ when the thickness of part is less than $1 \mathrm{~mm}$. $A$ is $647600 \mathrm{~mm}^{2}$ for the process condition, so the binder force $F$ approximately equals $1295 \mathrm{kN}$.

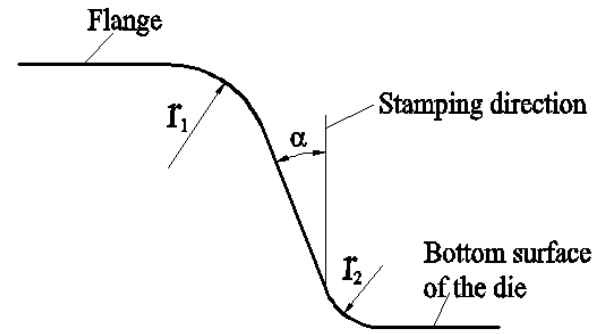

Figure 3. Schematic diagram of the addendum surface 
Table 2 Settings of process parameters

\begin{tabular}{|c|c|c|c|c|c|}
\hline \multirow{2}{*}{ No. } & \multicolumn{2}{|c|}{$\begin{array}{l}\text { Fillet of addendum } \\
\text { surface/mm }\end{array}$} & \multirow{2}{*}{$\begin{array}{c}\text { Binder force } \\
F / \mathrm{kN}\end{array}$} & \multirow{2}{*}{$\begin{array}{l}\text { Die clearence } \\
\text { C/kt(mm) }\end{array}$} & \multirow{2}{*}{$\begin{array}{c}\text { Friction } \\
\text { coefficient } \\
\quad f\end{array}$} \\
\hline & $\begin{array}{l}\text { Fillet of the } \\
\text { die } r_{1}\end{array}$ & $\begin{array}{l}\text { Fillet of the } \\
\text { punch } r_{2}\end{array}$ & & & \\
\hline 1 & 10 & 5 & 1000 & & \\
\hline 2 & 20 & 15 & 1300 & $1.1 \mathrm{t}$ & 1.25 \\
\hline 3 & 25 & 25 & 1500 & & \\
\hline
\end{tabular}

Effect of the Fillets Radii of Addendum Surface on Forming Property. Three conditions of fillets radii of addendum surface are simulated according to the process parameters of Table 2, and the thickness variations of the drawed parts under various conditions are shown in Figure 4.

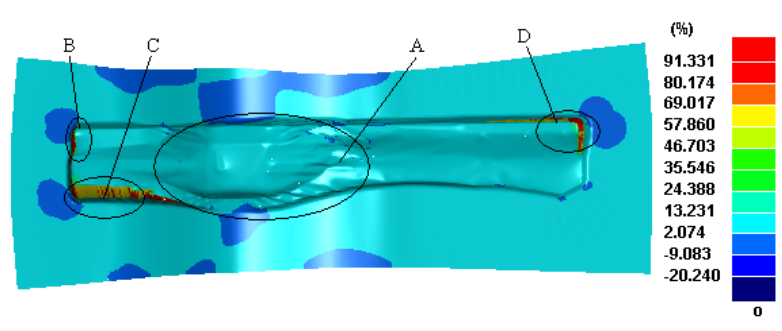

(a) $\mathrm{r} 1=10 \mathrm{~mm}, \mathrm{r} 2=5 \mathrm{~mm}$

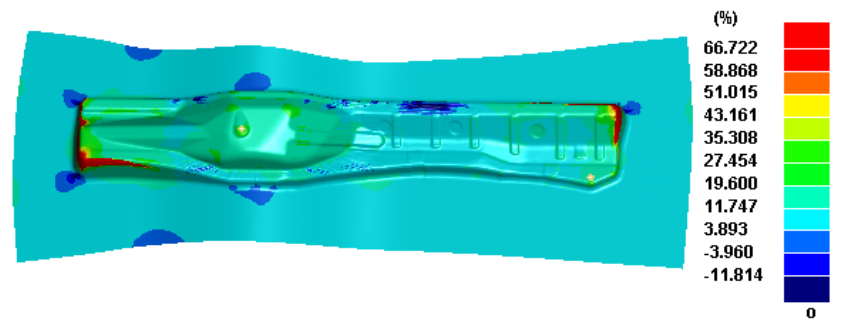

(b) $\mathrm{r} 1=20 \mathrm{~mm}, \mathrm{r} 2=15 \mathrm{~mm}$

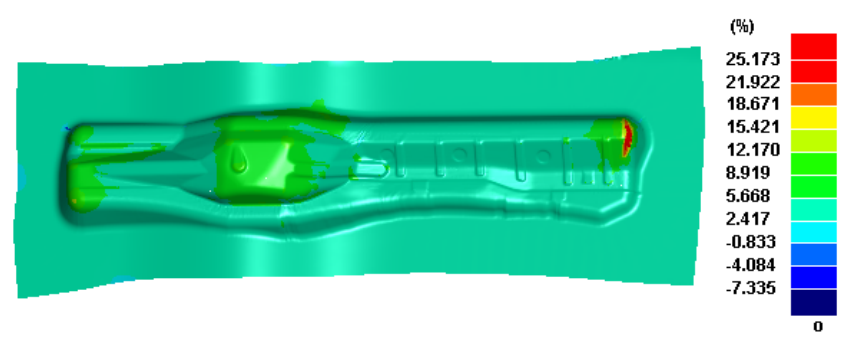

(c) $\mathrm{r} 1=25 \mathrm{~mm}, \mathrm{r} 2=30 \mathrm{~mm}$

Figure 4. Thickness variation under different fillets radii of addendum surface

It is shown in Figure 4a that both top edges of the part, as shown in B, C, D of Figure 4a, appear obviously thinning when fillets radii are small, and the maximum thinning rate is over $90 \%$. The wrinkling appears on the flange of the part, under the condition of certain binder force, the smaller fillets radii of addendum surface, the greater the resistance forces when the metal flows into the cavity, so the greater wrinklings generate on the part. The area $\mathrm{A}$ in the Figure 4a appears obvious wrinkling, which is the role of not fully forming due to the obvious fracture at the top of the part. As the bulge near $A$ in Figure 4a is large, the deformation requires lots of metal. When flowing into the die cavity, the metal firstly accumulates near the bulge in form of obvious wrinkle. As drawing process continues, the metal wrinkled gradually flattens to form the bulge. Both sides of parts fracture in forming process when the transition fillets radii are small, thus the part is not completely formed, and wrinkling reserves on the part not fully formed.

It is shown in Figure $4 \mathrm{~b}$ that with the increase of transition fillets radii of addendem surface, the forming of the part is more fully, but the maximum thinning rate is still very large, reaching $66 \%$. In the Figure 4c, the fillets radii of addendum surface are the biggest, namely $r_{1}=25 \mathrm{~mm}$ and $r_{2}=25$ $\mathrm{mm}$, the forming quality of the part is better, the maximum thinning rate is only $25 \%$, and the thickening effect of the flange is not obvious, so the fillets radii are reasonable.

Effect of the Binder Force on Forming Property. Three conditions of binder forces are set according to the Table 2 and the drawing processes are simulated by software Dynaform. As for the radii of fillets on addendum surface, $r_{1}$ equals $25 \mathrm{~mm}$ and $r_{2}$ equals $25 \mathrm{~mm}$. The effects of three binder forces on thickness variation of the part are shown in Figure 5 . The thickness variations under the forces $F=1500 \mathrm{kN}, F=1000 \mathrm{kN}$ and $F=1300 \mathrm{kN}$ are shown in the Figure5a, Figure $5 \mathrm{~b}$ and Figure 4c respectively. 


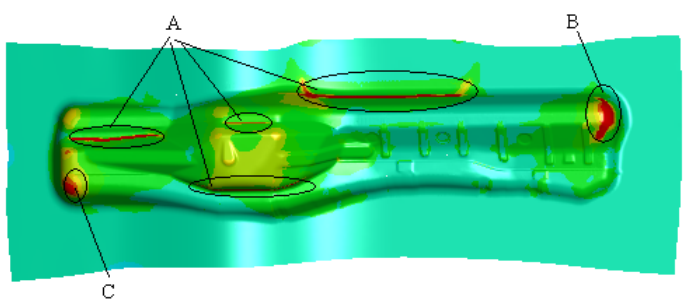

(a) $\mathrm{F}=1500 \mathrm{KN}$
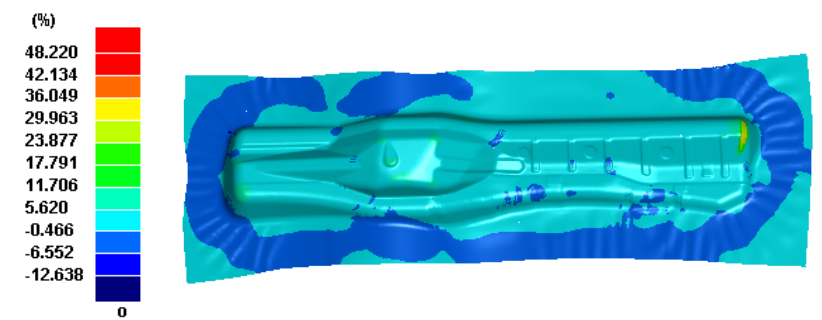

(b) $\mathrm{F}=1000 \mathrm{KN}$

Figure 5. Thickness variation under different binder force

It is shown in Figure 5a that the wrinkling on the flange of the part basically eliminates, but the area $\mathrm{A}, \mathrm{C}, \mathrm{B}$ and $\mathrm{D}$ in the Figure $5 \mathrm{a}$ are the significantly thinning area, with the maximum thinning rate up to $48 \%$. Binder force is the smallest in Figure $5 \mathrm{~b}$, but obvious wrinkles appear on the flange of the part with the thickening rate up to $21 \%$, slight wrinkles also appear on the local positions of the part, and the maximum thinning rate appears at the top of the part with the maximum thinning rate up to $15.53 \%$. In Figure 4c, binder force is $1300 \mathrm{kN}$, forming quality of the part is better, the maximum thinning area appears on the top corner of the part with the maximum thinning rate up to $25.17 \%$, and the thickening rate of the flange is smaller with the maximum thickening rate only $5.5 \%$, so the forming effect of the part is good under the condition. Taking into account the forming effect under 3 conditions, the binder force should select $1300 \mathrm{kN}$, which is close to the theoretical value and is only 1.05 times of the theoretical value.

\section{Conclusions}

The fillets radii of the addendum surface have great effect on forming of the part. When the fillets radii are small, serious fractures appear on the end tops of the part, thus the part can not fully deform. With the increase of the fillets radii, the fracture at the end top and thickening on the flange decrease, and the forming quality improve. The optimized process parameters are that $r_{1}=25 \mathrm{~mm}$ and $r_{2}=25 \mathrm{~mm}$.

When binder force is small, obvious wrinkling appear on the flange and local positions of the part. With the increase of binder force, the wrinklings on the part significantly decrease, but fractures on the end corner and the deep drawing area increase. When the binder force is $1300 \mathrm{kN}$, defects of fracture and wrinkling are the least, so $F=1300 \mathrm{kN}$ is the optimized parameter, which is the 1.05 times of the theoretical calculation value.

\section{Acknowledgements}

This work was financially supported by the Natural Science Foundation of Shijiazhuang Science and Technology Department (12108151A, 141081321A), and the School Established Research Foundation of Hebei University of Science and Technology (TY16).

\section{References}

- [1] Jian Lan, Xianghuai Dong, Zhigang Li. Inverse finite element approach and its application in sheet metal forming. Journal of Materials Processing Technology, Volume 170, Issue 3, 2005, Pages 624-631.

- [2] Hongyang Qiu, Yajuan Huang, Qiang Liu. The study of engine hood panel forming based on numerical simulation technology. Journal of Materials Processing Technology, Volume 187-188, 2007, Pages 140-144.

- [3] Y. Liu, X. Peng, Y. Qin. FE simulation for concurrent design and manufacture of automotive sheet-metal parts. Journal of Materials Processing Technology, Volume 150, 2004, Pages 145-150. 
- [4] W. Chen, Z.J. Liu, B. Hou, R.X. Du. Study on multi-stage sheet metal forming for automobile structure-pieces. Journal of Materials Processing Technology, Volume 187-188, 2007, Pages 113-117.

- [5] Keshan Diao, Meng Cao, Haomin Jiang, et al. FEM and experiment analyses of stamping process for AHSS part. Journal of Plasticity Engineering, Volume17, Issue3, 2010, Pages 66-69. (in Chinese)

- [6] Ze Li. Simulation and Process Optimization In Automotive Panel Stanping. Chongqing: Chongqing University, 2010. (in Chinese)

- [7] Wenlin Chen, Zhijie Li, Shaoyang Wang. Numerical Simulation and Parameter Optimizing of the Stamping Forming Process of Auto Front Panel. Journal of Netshape Forming Engineering, Volume3, Issue 3, 2011, Pages: 15-19.(in Chinese) 